\title{
O elogio das mulheres em contextos funerários da Atenas Clássica: estudo de caso do táphos de Mélita*
}

\author{
Marta Mega de Andrade**
}

\begin{abstract}
ANDRADE, M.M. O elogio das mulheres em contextos funerários da Atenas Clássica: estudo de caso do táphos de Melita. Revista do Museu de Arqueologia e Etnologia, São Paulo, 20: 235-249, 2010.
\end{abstract}

Resumo: Este artigo analisa uma estela funerária do Museu Arqueológico do Pireu (inv. 20), subentendendo sua pertença ao conjunto maior das estelas funerárias com dedicações a mulheres na Ática dos periodos arcaico e clássico. Procura levantar questões teórico-metodológicas pertinentes para o campo dos estudos de gênero, em geral, e da história das mulheres, em particular, além de propor hipóteses para a questão dos ideais normativos e sua mobilização pela sociedade poliade, no que concerne ao casamento, amor e aparição pública das mulheres.

Palavras-chave: Iconografia - Epigrafia - Contextos funerários - Philia Exposição pública das mulheres - Atenas Clássica - Relações de gênero.

\begin{abstract}
partir da observação de um artefato, mais precisamente uma estela funerária que encontramos na reserva técnica do Museu Arqueológico do Pireu (inv. 20), proponho neste artigo algumas questões sobre a exposição feminina em contextos funerários atenienses. Originária da região do Pireu (com grande probabilidade), datada de 360-50 a.C. (segundo Clairmont 1970:117-119), a estela foi dedicada a uma certa Mélita. No que tange aos estudos recentes sobre espaços funerários, o
\end{abstract}

táphos de Mélita não parece ter merecido, até o presente, abordagens próprias. ${ }^{1}$ Espero demonstrar, contudo, que em sua especificidade essa estela funerária suscita um interesse historiográfico particular para os estudos da história das mulheres na polis clássica.

Ao ver a pequena estela ser trazida no colo pelo funcionário da reserva técnica do museu, não pude nem quis deixar passar um instante de mistério. Fetiche do objeto? Que assim seja: fui "enfeitiçada" pela mística "coisa em si" e, com algum distanciamento temporal e espacial

(1) Aparece em estudos de escultura funerária e epigrafia grega, sendo os mais recentes Clairmont (1970: 117-119; 1993: 489-491) e Hansen (1989: 530). Raramente surge como referência em publicações: há uma rápida menção ao epigrama em Humphreys (1983: 108) e ao monumento como um todo em Younger (2002: 183). 
desse evento, reconheço hoje que não pretendo abrir mão dessa representação; não pretendo acabar com os efeitos desse estranhamento, temerário mas absurdamente fundamental para começar a dizer qualquer coisa verdadeira em história. Assim, não se trata de desfazer aquele objeto que eu vi, em meio a outros tantos pedaços de artefatos antigos em uma reserva técnica, desfazê-lo em pesos, medidas, materiais básicos, técnicas e estilos. O que proponho aqui é que nos deixemos enlevar, radicalmente, pela fantasia da coisa, que é propriamente a sua humanidade, deixando o artefato abrir passagem a um diálogo humano com as coisas humanas. Isso define, de modo conciso, aquilo que compreendo por "interesse historiográfico", diferente do artístico ou literário, não pela ciência que propõe, mas pela arte de fazer ver e ouvir, através dele, vozes das mais diversas, aproximando-as; em uma palavra, criando empatia - ou escutando a musa - para conceber um passado.

\section{A "coisa em si"}

Como objeto com que deparamos no contexto de um museu onde é classificado em meio a outros, tomado em um conjunto e interpelado estatisticamente, a estela de Mélita é mais um "exemplar" dentre as centenas de estelas funerárias com o mesmo padrão de modelagem da peça e da iconografia: pequena e estreita, medindo $90 \mathrm{~cm}$ de altura por $28 \mathrm{~cm}$ de largura, encimada por um antêmio (Foto 1$)^{2}$. Logo abaixo do antêmio encontra-se um epigrama (Fotos 2 e 3), onde descobrimos que essa estela era dedicada a uma mulher de valor, chamada Mélita. Abaixo dele vem a imagem

(2) Todas as fotos utilizadas neste artigo são de minha autoria e pertencem ao arquivo da pesquisa Contextos Funerários e Exposição Feminina em Atenas. Agradeço imensamente ao $26^{\circ}$ Eforato de Antiguidades PréHistóricas e Clássicas por ter permitido meu acesso, e agradeço ainda particularmente à arqueóloga do Museu do Pireu, Dra. Angeliki Poulou, que me acompanhou ao longo da visita. Para fotos da estela inteira, ver Clairmont 1970, pl. 19 no. 39; 1993, fig. 2406. talhada, em forma ligeiramente retangular, com $24 \mathrm{~cm}$ de largura por pouco mais de $26 \mathrm{~cm}$ de altura (Fotos 3 e 4a). Esse conjunto encontra-se perfeitamente preservado, salvo por algumas ranhuras nas bordas que não comprometem nem o texto do epigrama nem a cena gravada na pedra.

A iconografia em relevo apresenta de modo centralizado uma cena de aperto de mãos (dexiosis) entre a figura feminina sentada à esquerda e a figura masculina em pé, à direita (observar detalhes nas Fotos 4b e c). Em Gravestone and Epigram (1970: pl. 19, fig. 39; de agora em diante citado como GaE), Clairmont identifica a figura feminina sentada com a esposa falecida, enquanto o homem de pé representaria o marido, ambos mencionados no epigrama. Já em Classical Attic Tombstones (1993; a partir de agora citado como CAT), o mesmo Clairmont inclui a estela de Mélita no contexto das cenas com "dois adultos", enfatizando a dexiosis e assumindo como premissa tratar-se de uma relação marido/esposa em que as figuras representadas corresponderiam às personagens mencionadas no epigrama (p.489-491). No campo da História da Arte, Benson apresentou em 1996 a monografia intitulada Recurrying Figure-Types on Classical Attic Grave Stelai, nela buscando analisar padrões iconográficos das estelas funerárias áticas em um contexto mais amplo. O padrão representado na estela de Mélita é classificado nesse estudo como o de "figura feminina sentada à esquerda e figura masculina de pé”. Embora esse trabalho seja ainda fundamentado em uma abordagem do estilo e suas variações, a autora contribui

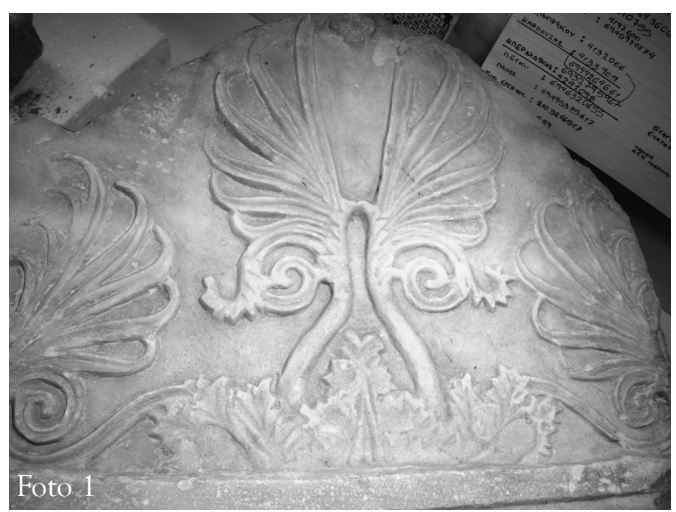



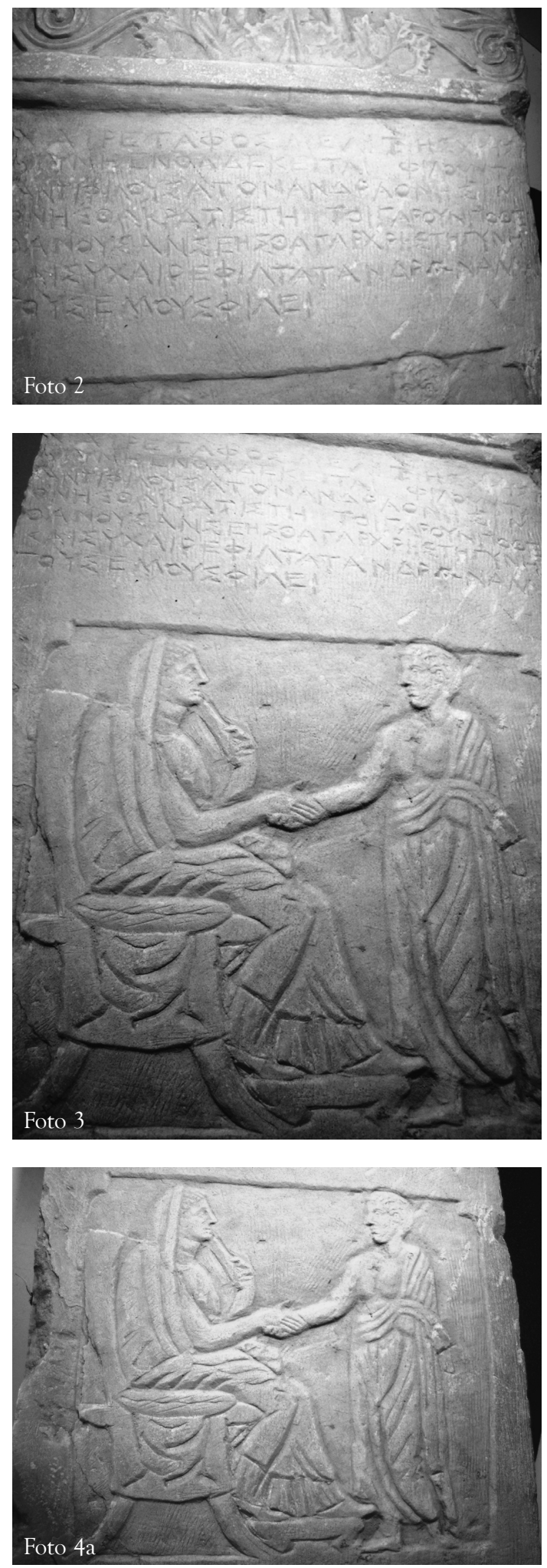

conosco ao refletir sobre a mobilidade dos padrões, vinculando-a às demandas da clientela ao invés de enfatizar a simples cópia ou difusão interna ao "estado da arte" (p.14). Benson afirma, por exemplo, que, tomadas individualmente, as estelas funerárias eram provavelmente dispensáveis para o ritual; sendo assim, sua utilização ou não dependeria mais de preocupações com um public display das familias comanditárias do que da necessidade (religiosa) de representar ou identificar parentes mortos, desta ou daquela forma. Isto quer dizer que aquilo que a iconografia da estela funerária expunha mesmo quando mostrava as mesmas imagens com algumas variações - dependeria de um circuito que envolvia as demandas da clientela tendo em vista a dimensão da família em suas necessidades rituais, mas ainda em sua prática de exposição pública. Nesse âmbito, a identificação das pessoas e a remissão a um relacionamento dos vivos com os mortos devem ser compreendidas como um uso possivel dessa iconografia, não como a sua intenção primeira.

Analisando os elementos principais desse padrão iconográfico, teremos no centro da cena o aperto de mãos entre o homem e a mulher. O motivo da dexiosis é mais do que comum, quase predominante, na arte funerária do século IV a.C. Todavia, não apenas em contextos funerários, mas em outras esferas como a das relações politicas, a diplomacia entre poleis, a arte votiva etc., o aperto de mãos se insere em uma pluralidade de conotações. Em relação aos contextos funerários, Pemberton enumera algumas delas: obrigação legal dos filhos com o funeral dos pais; a obrigação do herdeiro em prover sepultura; sentimento de abandono ritual provocado pela praga (finais do século V a.C.) e necessidade de reafirmar a prática correta etc., revelando, com isso, opção pelo significado da dexiosis como símbolo da união e da concórdia da família diante dessas questões (1989: 4550). Ao ampliar o foco da visão para a iconografia do mundo greco-romano em geral, Davies afirma: 


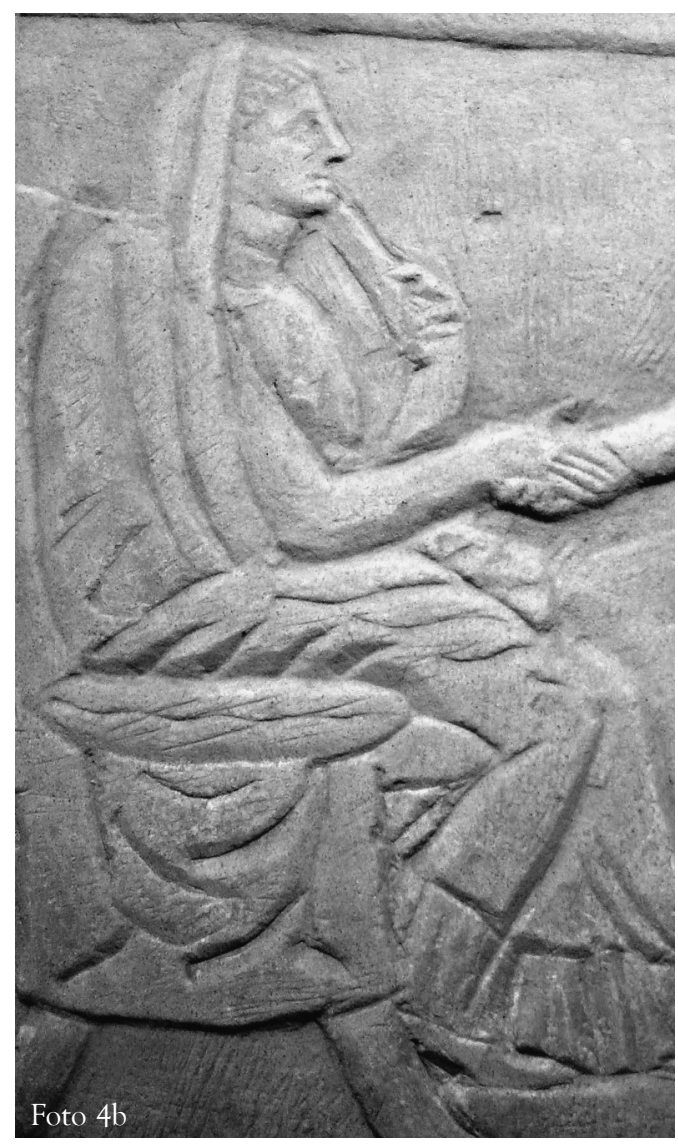

The handshake emerged as a major funerary motif on classical Athenian grave stelai, but its appearance on these monuments should not be studied in isolation. Vase painting of the late Archaic and Classical periods used the motif in a wide variety of contexts: it was associated with the heroes Herakles and Theseus in scenes which imply the granting of status, in scenes in the Underworld and in scenes of marriage and agreement, and particularly in scenes of greeting and parting. In view of this rich array of associations it seems unnecessary to define too closely the "meaning" of the handshake on the grave stelai: it may have been precisely this multiplicity of associations that made the motif such a suitable one for monuments that were generally chosen from stock rather than made to an individual design. But perhaps it was the themes of

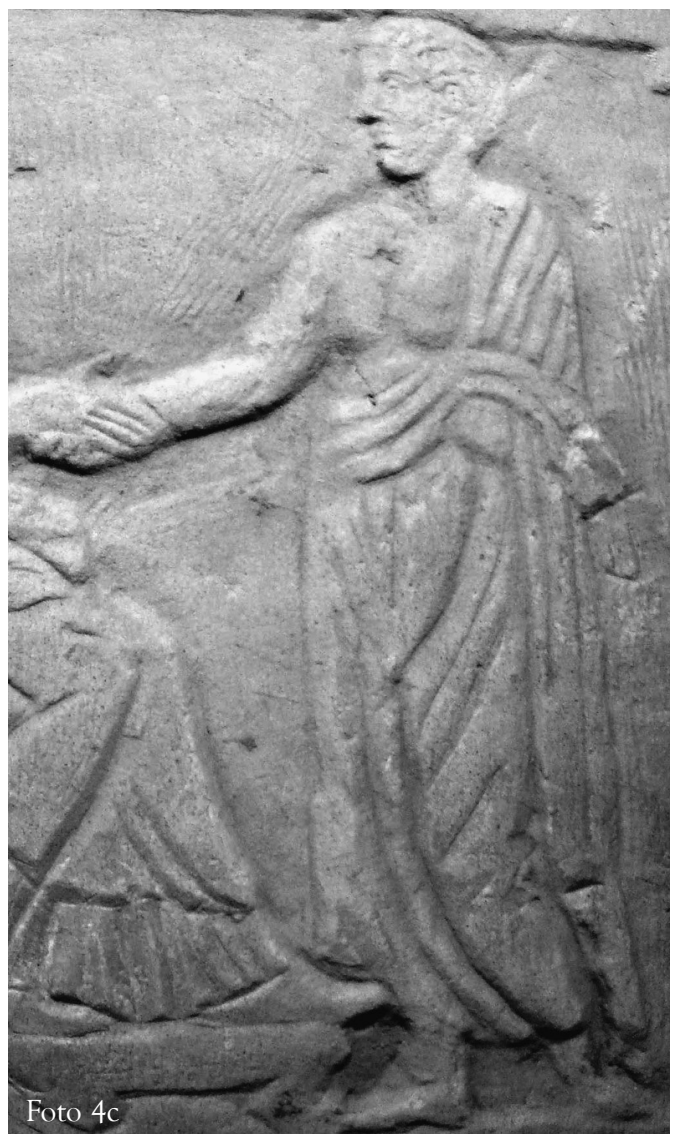

parting at death and reunion of the family in the afterlife that would have been uppermost (1985: 639).

Pemberton e Davies parecem concordar com a predominância do aspecto ritual e das crenças religiosas na exploração do motivo da dexiosis pela iconografia funerária. Apesar disso, Davies conclui que não se deve definir um sentido de forma tão estrita, dada a pluralidade de contextos em que o aperto de mãos aparece representado. Abre caminho, com isso, para que reflitamos sobre a flexibilidade das conotações que um tema iconográfico altamente repetido precisa permitir. É importante investigar essa possibilidade de conotações plurais, pois acredito que essa polissemia, aliada à alta padronização do gestual, pode ter sido razão fundamental para a escolha da dexiosis e de seus elementos correlatos na estela de Mélita. 
No plano central, o aperto de mãos entre uma mulher sentada e um homem barbado, de pé. Enquanto estende a mão direita ao aperto da mão direita da figura masculina, a mulher levanta o véu com a mão esquerda. Não há muitos detalhes, além do penteado e das roupas; e o estilo do talhe é simples, quase tosco como se inacabado - Clairmont demonstra até uma certa impaciência com isso (CAT 2406) - de modo que as vestimentas e as feições das personagens não oferecem muito mais à observação. Os elementos da cena parecem, então, plenamente descritos: dois adultos, um homem e uma mulher, sendo o homem de pé e a mulher sentada, trocando um aperto de mãos enquanto a mulher levanta o véu. Na medida em que o epigrama funerário nomeia Onésimo e Mélita, a identidade dos dois adultos parece dada; ao mesmo tempo, a utilização da dexiosis no mesmo plano que o ato feminino de levantar o véu parece confirmar que se trata da esposa elogiada por seu marido. Aparentemente, mas o "aparentemente" não deve ser tomado como recurso retórico daquele que descreve. As "aparências" podem ser aqui, no caso da estela de Mélita, relevantes para a compreensão do contexto.

Deixando de lado a questão da identidade do casal, um outro ponto de vista sobre o conjunto da cena deve ser mencionado. $\mathrm{Na}$ década de 1950, Johansen (1951) propôs um sentido religioso para a iconografia das estelas funerárias gregas: ${ }^{3}$ essas estelas seriam fundamentais para os ritos funerários, na medida em que proporcionavam a possibilidade operatória de cultuar os mortos tanto por constituírem signos de um local de sepultamento como por encarnarem a função de objetos (iconográficos) votivos. Assim, após comparar relevos funerários do mundo grego, Síria, Mesopotâmia e Egito, o autor ressalta a função cultual da estela funerária para definir seu valor artistico,

(3) "In the features mentioned in the preceding pages, the religious substratum wherein the classical attic grave-reliefs were deeply rooted comes to the surface. They prove that on these reliefs the religious ideas embodied in their predecessors live on active till the very latest phase." (Johansen 1951: 164) afirmando que a arte funerária dos gregos deve ser compreendida a partir do papel fundamental que desempenhava no culto aos mortos, contribuindo para sua heroicização/deificação. ${ }^{4}$ Aplicada ao padrão de representação na estela de Mélita, a tese de Johansen implicaria a compreensão de que o indivíduo "entronizado" (a figura feminina) seria o morto ao qual se dirigem os vivos em reverência. Essa deferência dos vivos em relação aos mortos seria encarnada na representação da dexiosis, aliada à recíproca da figura feminina - levantamento do véu como gestos de comunicação (e reciprocidade) entre os seres comuns e os seres mais do que comuns, os mortos divinizados.

Esse ponto de vista teve defensores mais ou menos explícitos antes de Johansen, e ainda inspira simpatia dos especialistas, graças à premissa religiosa que subentende. Mas o subentendido (preeminência da religião nas relações sociais e coesão da sociedade poliade), aplicado aos espaços funerários, depende em grande medida da conexão que nós mesmos fazemos entre o âmbito da morte e as instituições religiosas de nosso tempo. Parece "natural" pensar as crenças e práticas em torno da morte como dirigidas ao sagrado, ao diálogo com um mundo divino ou com o além, enfim, como tema atinente ao que reconhecemos como "religiosidade". Contudo, é possivel nuançar essa determinação religiosa univoca do monumento funerário questionando, por exemplo, a forma monolitica como essa religiosidade pressuposta por Johansen subentende as crenças na vida após a morte (seria preciso provar que diversos povos, incluindo gregos e

(4) Em Reading Greek Death (1995: 108-216, 413-444), Sourvinou-Inwood apresenta outra hipótese. Ela indica uma sensivel mudança na relação com os mortos entre os periodos arcaico e clássico, quando um contexto de heroicização/deificação teria conduzido à valorização do morto expressa pela saudação chaire, "salve". Embora concorde com a tese de que a saudação pertenceria a um contexto heróico, não me parece que a conclusão necessária da argumentação seja pela heroicização/ deificação do morto, mas pela inserção cada vez mais acentuada do louvor de tipo heróico nos ritos funerários das pessoas comuns, quer dizer, pessoas que não necessariamente pertenciam ao círculo aristocrático. 
atenienses do periodo clássico, acreditavam na permanência da identidade pessoal após a morte, ou ainda que para todos esses povos os mortos eram como seres divinos). Certamente, a preocupação com os ritos funerários era uma atitude tida como correta pela moralidade popular. Mas isto não significa que o "sagrado" constituia a única potência em ação nesses ritos, que eram inclusive ocasiões, pretextos, para o public display das familias, como enfatiza Benson (1996: 159-209), mas ainda como afirmam Humphreys (1983:79-130), Garland (1985:1-37, 104-120; 1989: 1-15), Morris (1992: 103-127; 1993: 35-50) e todo um conjunto de pesquisadores para quem a estela funerária deve ser compreendida também numa dimensão social de exposição, prestigio e status, mesmo que sua origem esteja no ritual. Separar a dimensão religiosa dos nomizomena funerários de sua dimensão politica é um equivoco que distorce sua correta contextualização.

Assim, precisamos nos voltar para um âmbito mais corriqueiro, para a intima relação entre a função de prolongar os efeitos visuais do ritual adequado - ao que também se dava o nome de táphos ${ }^{5}$ - e a necessidade de reiterar, por meio desse táphos, imagens de relações idealizadas do universo doméstico das familias, tendo em vista uma sociedade mais vasta, um olhar público sobre esse convivio. Enfatizaria o gesto da mulher sentada a levantar o véu não como uma forma de representar a divindade, mas como um modo de fixar as virtudes da boa esposa; gesto que evoca o aidós (o pudor ou reverência) da noiva, tema cuja ubiquidade é incontestável na iconografia ática do casamento (Lissarrague 1991: 163 ss; Rehm 1994: 40 ss.; Leader 1997: 695). Na estela de Mélita, a figura feminina sentada que levanta o véu e estende a mão direita para a dexiosis relembra a concórdia respeitosa que reina no interior da casa, a mulher sob a condução do marido em uma relação em que impera o domínio do universo masculino temperado pela reciprocidade.

(5) Segundo Lidell; Scott, Greek-English Lexicon, 1996 (LSJ), "funeral rites".
São signos indicativos de um relacionamento valorizado entre marido e esposa - pudor, deferência, respeito e philia -, sugerindo a conformação de ambos ao modelo, levando o olhar do observador a reconhecer, pela própria monotonia do padrão inúmeras vezes repetido da estela, por hábito, uma classe de fatos socialmente relevantes mesclada, para fins de exposição pública, a representações recorrentes na iconografia votiva (comunicação humano/ divino). Com isto, não estou propondo a chavemestra de interpretação de um paradigma iconológico, mas uma "leitura" possivel para a presença desse padrão iconográfico na estela de Mélita. Pois mesmo a repetição exaustiva do padrão não pode nos levar a concluir que em cada um de seus "casos" de uso o motivo iconográfico foi escolhido por dizer sempre a mesma coisa, nem mesmo podemos afirmar que se the escolhia porque queria dizer alguma coisa, intencionalmente. Assim, para evitar o engessamento em uma chave-mestra de interpretação iconológica, é preciso explorar o modo como esse padrão é proposto e reproduzido como padrão, no "caso" especifico do táphos de Mélita, e assim como o padrão pode ser e é mobilizado, flexivel aos usos de seus comanditários.

Surge, então, o entalhe do epigrama, um texto, entre a iconografia e o antêmio. Nesse texto, encravado na pedra com traços simples, há indicações sobre para quem a estela é dedicada, qual a importância dessa pessoa para o dedicante e, ainda, qual a importância da própria estela.

Diz o epigrama:

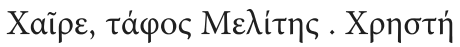
$\gamma v v \eta \dot{\varepsilon} v \theta \dot{\alpha} \delta \varepsilon \chi \varepsilon \tilde{\varepsilon} \tau a !$

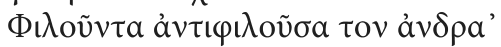

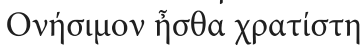

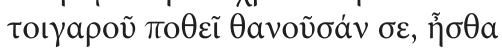

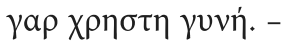

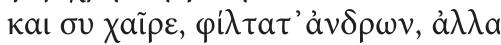

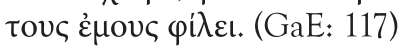

A tradução que proponho é a seguinte:

Salve, túmulo de Mélita. Jaz aqui uma mulher de valor. Amante de seu amante homem Onésimo, eras a 
preponderante. Por isso ele continua lamentando a tua morte: eras uma mulher de valor. - salve, também, mais querido dos homens, ama os meus.

Ao referir-se ao táphos de Mélita, o epigrama evoca a imagem do túmulo, construção especifica de uma prática funerária vinculada a um ritual; não se refere, preferencialmente, nem à função sígnica do marco (sema) nem ao epitáfio (memorial), mas à configuração física do lugar onde um rito apropriado originou um sepultamento. Assim, podemos inferir que a estela, se algum dia foi usada como marco funerário, não deve ter funcionado como um cenotáfio, apenas, mas foi concebida para identificar o local onde o corpo de Mélita encontrava-se sepultado. Em segundo lugar, se a interpretação discutida aqui for correta, é provável que a estela dedicada a Mélita tenha sido concebida para formar um conjunto com o montículo sobre cista muito comum nas necrópoles áticas. Isto quer dizer que a estela de Mélita não parece ter feito parte de um recinto familiar (peribolos), tanto pela ênfase dada ao táphos quanto pelo modelo do epigrama inscrito. Nos periboloi, os monumentos funerários dispunham-se dentro da área delimitada do recinto, sem relação fisica imediata com o local do sepultamento de um indivíduo comemorado, de tal modo que todo o conjunto do peribolos poderia ser tomado como um só táphos (Benson 1996: 159 ss). Além disso, o epigrama menciona a relação amorosa entre um homem e uma mulher sem indicação de parentesco entre ambos e/ou da mulher com outros parentes, o que também não é de praxe nesses periboloi (Garland 1985: 104 ss; Closterman 1999: 158 ss).

A saudação inicial - chaire - é extremamente comum nos epitáfios da época; sugere um encontro, pretexto para entabular uma conversa cuja representação depende da leitura em voz alta. "Salve!": isto não se lê, mas se diz. Se fosse concebida para fazer parte de um recinto familiar, a pequena estela de Mélita ficaria um tanto escondida, tornando quase impossivel a verbalização (ou a encenação) do diálogo que subentende quatro interlocutores, ao menos: a estela que é saudada pelo transeun- te; este último que, ao saudar o táphos de Mélita, se faz leitor-espectador e descobre que "jaz aqui uma mulher de valor"; o homem, Onésimo, a quem o epitáfio se refere em terceira pessoa, como se ausente ou impossibilitado de falar, para elogiar a mulher que, "amante de seu amante homem, era preponderante"; Mélita, por fim, fala em primeira pessoa, não ao transeunte que deu vida à conversação, mas a Onésimo, a quem saúda e pede que ame os seus.

O epigrama foi composto, assim, em quatro versos, sendo dois hexâmetros datilicos "irregulares" (para dar lugar à expressão philounta antiphilousa, no mesmo verso) e dois hexâmetros trocaicos. Subentendendo que o transeunte que observa e lê em vOz alta traz à luz do dia uma conversação, esses versos são incomuns para o periodo do qual a estela é datada, meados do século IV a.C.. Nesta época predominam as estelas sem epigrama, que compreendem como escrita apenas um ou mais nomes, seguidos do nome do marido, ou do pai, ou disso tudo mais um demótico; quando os epigramas estão presentes, o formato dialogado não é usado, assim como raramente o texto remete o leitor ao monumento em si. Essas referências, comuns no século VI e presentes no século $\mathrm{V}$ a.C. (principalmente nos lécitos de fundo branco, onde constatamos a importância do monumento funerário na iconografia dos ritos), haviam caído em desuso no século IV a.C., em proveito de um memorial cuja tônica, na maioria dos casos e pensando apenas nos epitáfios femininos, recaia sobre o louvor (virtude, prudência, pudor etc.) do individuo em terceira pessoa, mencionando, no máximo, os parentes e amigos envolvidos na dedicação funerária. ${ }^{6}$

O epigrama dedicado a Mélita é, portanto, incomum, instigante e intrigante.

(6) Cf. Andrade, 2009. Conferência ainda não publicada, divulgando dados da pesquisa Contextos Funerários e Exposição Feminina em Atenas. O catálogo de dedicações funerárias a mulheres na Ática deve ser publicado até meados de 2011. 


\section{Uma leitura da leitura}

- Salve, túmulo de Mélita. Jaz aqui uma mulher de valor

Após identificar o túmulo como sendo de Mélita, o epigrama introduz o elogio: uma mulher de valor. Younger (2002: 183), citando por sua vez Nielsen (1989: 419), afirma que Mélita seria uma escrava, ou uma mulher de origem escrava, por conta da combinação da saudação chaire (raramente usada para cidadãos, segundo Nielsen) ${ }^{7}$ com o atributo chresté ("valorosa"). Embora eu tenha certa reserva com o fechamento da questão (chresté = escravo), devemos observar que a exaltação desse tipo de valor tem uma conotação doméstica (um individuo valoroso do ponto de vista das atividades cotidianas da vida comum) e é uma inovação que ganha força no século IV a.C. Acredito ser muito difícil determinar que todos os usos desse atributo liguem-se a escravos ou escravas; mas acredito, também, que todos os usos desse atributo remetem a um convivio doméstico, dai podendo ser referido a escravas, escravos, libertos e livres, como as mulheres, girando em torno de uma cena de sociabilidade e trabalho na vida cotidiana das casas. Talvez tenhamos ainda uma boa pista para quem busca referências sobre a pertença dos individuos comemorados nas estelas funerárias a grupos sociais determinados, já que o "valor", neste caso, não é a virtude heróica (arete), mas a pragmática chrésis. ${ }^{8} \mathrm{O}$ predomínio da vida doméstica como contexto do valor, somado a um elogio do qual as expressões heróicas encontram-se ausentes, aponta para a procedência não aristocrática dos comanditários e, ao

(7) Nielsen (1989: 419 ss.) constata que o uso de chaire é raro entre cidadãos, através de uma análise quantitativa dos epigramas áticos do periodo. Contudo, talvez antes de vincular o enunciado ao status cidadão ou sua falta, melhor perguntar se a saudação não seria uma evocação dos encontros cotidianos, da vida comum e do mundo do trabalho, onde justamente a cidadania ou sua falta deixariam de ser parâmetros absolutamente dominantes. (8) Segundo referência de Lidell; Scott, Greek-English Lexicon, 1996 (LSJ), essa prestatividade do chrestos pode ser lida também em sentido erótico. mesmo tempo, aponta para um valor positivo do pragmatismo cotidiano.

- Amante de seu amante homem

Onésimo, eras a preponderante

Onésimo é o amante daquela que retribui ativamente seu amor. Não vejo paralelo entre esta sugestão e qualquer outro elogio funerário comum no periodo. Como se se tratasse de uma disputa, dois lados entram em contenda e se põem um diante do outro: philoûnta antiphiloûsa ("a que ama em retribuição ao amante") ${ }^{9}$ reciprocidade subentendida em formas poéticas e épicas do discurso amoroso (Calame 1996: 53-63). O cuidado em não tornar passivo um dos lados resolve-se nessa construção verbal que torce o hexâmetro para confirmar o enunciado seguinte: "eras a preponderante", sugerindo dois adversários e um vitorioso no contexto de uma disputa. Isto quer dizer que, numa relação de diversos concubinatos domésticos, Mélita era a principal consorte? Ou significa que, no interior da relação do casal homem-mulher, quem preponderava era Mélita - homenagem simbólica a uma boa esposa falecida? Ou quer dizer que Mélita, que amava, não pode ficar sozinha com o crédito da ação amorosa e deve atribuir a Onésimo o seu quinhão? Ou tudo isso ao mesmo tempo? Por seu turno, de Onésimo dirá Mélita, em seguida, que era "o mais querido dos homens", sugerindo também a competição: entre mulheres em relação a Onésimo, entre homens em relação a Mélita, e entre Mélita e Onésimo pelo kratos no amor. Mélita era, assim, a melhor amante, enquanto Onésimo era dos homens o mais querido.

Essa disputa pela preponderância no amor reciproco surpreende aquele que observa a iconografia da estela e pode inferir, dela, signos de deferência e submissão da boa esposa, como o gesto do levantamento do véu. Surpreende

(9) Clairmont chama a atenção para a presença da fórmula philein antiphilein ("amar em retorno ao amar") em diálogos platônicos (Lysis 212 c-d; Fedro, 255d) e em Aristóteles (Ética a Nicômaco 1155b28, 1157b30, 1159a30; Ética a Eudemo 1236b2), utilizando-se dessa informação (dentre outras de caráter estilistico) para datar a estela em aproximadamente 350 a.C. (1970: 117). 
quem aguardaria uma correspondência entre a figura da boa esposa e um elogio de sua virtude e prudência, coisa que não acontece no epitáfio de Mélita. E apesar de Clairmont (1970: 117119) assumir que se trata de marido e esposa (pela presença de anèr e guné como qualificativos de Onésimo e Mélita), fico tentada a concordar em parte com Younger (2002), concluindo que Mélita (e talvez o próprio Onésimo) não pertenceriam ao círculo restrito dos cidadãos. Mesmo sem concordar a priori com a atribuição conferida pelo autor do status de escrava para Mélita, o indício de que não estariamos necessariamente diante de uma dedicação funerária de um marido cidadão a sua esposa cidadã/concubina não pode ser subestimado, pois aponta para um uso inusitado das imagens padronizadas da estela, fortemente vinculadas ao casamento ideal (não necessariamente o casamento entre cidadãos). Por outro lado, se Mélita e Onésimo, a despeito de nossas pressuposições, foram mesmo esposa e marido, cidadãos ou não, então a questão se tornaria ainda mais interessante, pois a tônica do elogio e do reconhecimento nesse relacionamento recairia, no epitáfio de Mélita, numa visão positiva do amor conjugal.

Essa positividade do amor conjugal é inesperada diante de todo um campo literário ${ }^{10}$ que nos proporciona uma visão do relacionamento conjugal "esfriada" pela parceria, complementar no oikos, do homem com sua mulher. Todavia, essas mesmas "obras" da "literatura grega" - penso aqui fundamentalmente na escola socrática - são dirigidas à formação do cidadão e não nos permitem generalizar valores altamente especulares para o conjunto da sociedade poliade. E se Mélita e Onésimo fossem um casal de metecos? Ou de escravos? Ou simplesmente de cidadãos que não se enquadrassem no grupo dos "belos e bons"? Poderiamos aplicar ao seu relacionamento os ideais normativos que perpassam $\mathrm{O}$ Econômico, de Xenofonte?

(10) Cf. Redfield 1994. Compreenda-se "campo literário" como no âmbito produzido dentro da tradição européia dos estudos clássicos, não como cultura literária ou letrada dos atenienses.
Em Le Vocabulaire des Instituitions IndoEuropéennes, E. Benveniste apresenta um estudo sobre philos, sua etimologia e campo semântico (1969: 335-353), em que enfatiza o valor afetivo ligado ao atributo: philos como "meu querido", além de "meu amigo". De um modo diferente, o substantivo philia, comum ao longo do periodo clássico, pode definir um âmbito de relações de amizade e concórdia abstrata entre "parceiros", sejam eles familiares, amigos ou cidades (Schein 1988: 179). Philia, como conceito, desdobra-se em uma história de parcerias em diversos niveis, alguns deles passiveis de abstração "amizade"; já philein (verbo no infinitivo), "amar" ou "beijar", além de constituir uma expressão mais antiga, desdobra-se em uma história de (empíricos) encontros. ${ }^{11}$

O relacionamento entre Mélita e Onésimo não é propriamente uma philia, mas um "amar" concretamente retribuido de forma ativa. São philoi, "queridos". Certamente, os tratados filosóficos sobre o amor e a amizade, que datam daquele periodo e influenciam o imaginário da (nossa) posteridade, deixam claro que os casamentos não se devem tramar pelas paixões, mas de preferência pelos interesses de familia; contudo, outros textos da Atenas clássica podem nos mostrar que o amor do casal - anterior, posterior ao casamento ou simplesmente hipócrita - mistura-se totalmente à coabitação, à partilha física do leito, ao desatar o cinto para a entrega ao marido. ${ }^{12}$ Por isso, não tenho como seguir a opinião de Konstan (1997: 91) para quem "the term philos was evidently employed in everyday language for the clients or partners of a courtesan", como caminho

(11) "Une valeur affective s'attache à phílos qui devient épithète ou terme d'adresse à l'égard de ceux qui vivent au foyer, que ce soit comme parents (...) ou comme familiers, telle la vieille nourrice (maia) Euryclée. Il sert de terme affectueux et cette qualité trouve, après Homère, une expression propre dans l'abstrait philia 'amitié', distinct de philotes, ainsi que dans l'acception courante, déjà homérique, du verbe philein 'aimer' (d'amour sensuel)" (Benveniste 1969: 346)

(12) Para a análise dessa positividade do amor conjugal, as peças do teatro, tragédias como Medeia ou Alceste, de Euripides, mas ainda uma comédia como a Lisístrata, de Aristófanes, são testemunhos fundamentais. Cf. supra: 15 16; Cf. Calame 1996: 123-145. 
estrito para compreender a relação que esse termo - phílos - designa. A qualidade de uma tal evidência depende, em larga medida, do tipo de metodologia que o autor aplica a suas fontes (sempre textuais), aliado a um bocado de préconcepção. A visão fria de uma estima entre cônjuges tem sido erroneamente, para nós, de grande naturalidade para definir o "mundo clássico", de forma que nossas expectativas parecem ser preenchidas quando se voltam para esse lado da moeda. Mas há um outro: assim como Euripides pôs em cena Andrômaca, colocou Medéia e Fedra. Assim como as estelas funerárias preenchem nossas expectativas visuais quanto à "concórdia familiar", os vasos (como as pyxides) mostram outra coisa, que não vemos. Preferimos falar de um gineceu, espaço de confinamento feminino, ao invés de conotações eróticas ligadas à iminência do casamento, veiculadas em pequenos vasinhos que as noivas ganham e manuseiam (Lissarrague 1995: 91101). Nem as muitas noivas dos vasos, nem as heroinas de Euripides passam por hetairai embora "cortesãs" e noivas tenham em comum, na imagética dos vasos assim como na poesia, Eros (Calame 1996: 123-145).

Voltando-nos para as estelas funerárias com epigramas, não podemos deixar de observar que esse amor concretamente retribuido, ativo, marca presença, embora não seja de todo comum, nos epigramas funerários. $\mathrm{O}$ oposto, um amor "frio" ou a "estima", por seu lado, não aparece explicitamente nos epigramas dedicados a mulheres mais do que os elogios da virtude e da prudência, ou as manifestações de saudades dos parentes; não aparece mais, em todo caso, do que esse amor ativo. ${ }^{13}$ Em grande parte dos casos, a pressuposição de que a relação valorizada entre marido e mulher e entre a mulher e seus familiares é uma relação de philia parece implicita na dedicação funerária. Então, teriamos que investigar se, por não ser um padrão para a descrição do relacionamento marido/esposa, o amor sensual teria que

(13) Alguns exemplos desse amor ativo encontramos em Peek 1988, Griechische Vers-Inschriften no. 343, 421, 495, $1415,1810$. ser explicitado para ser objeto de louvor e lembrança, enquanto a relação familiar/ conjugal fundada na philia seria, por seus simbolos, implicitamente reconhecida. No caso do táphos de Mélita, a iconografia nos convida a seguir a direção desse reconhecimento do implícito, enquanto o epigrama singulariza, enfatizando o amor dos amantes para além da philia que poderia - ou não - defini-los.

- salve também, mais querido dos

homens, ama os meus

O epigrama termina com a resposta de Mélita: Onésimo é, para ela, o mais querido dos homens e, por isso ela pede: "ama os meus". Humphreys (1983: 108) traduz este pedido como "kiss my children for me" ("beije meus filhos por mim"), tradução que reconduziria o epitáfio a um contexto familiar, mas que não se sustenta a não ser por uma longa grade de inferências. A tradução literal é preferivel, tal como Clairmont (GaE: 19, 39 [117]) a dispõe “ama os meus". Será necessário compreender o que isso quer dizer, ou o que a falecida Mélita deve ter querido dizer (ou devem ter querido que ela dissesse) com isso. Podemos supor, por exemplo, que tal requisição visaria resguardar o lugar dos filhos dessa mulher falecida em uma provável futura familia de Onésimo, para isso procurando manter na lembrança a força que essa mulher tinha na relação amorosa do casal. De qualquer maneira, é preciso compreender por que tous emous philei seria uma referência aos filhos e não aos "próximos" em geral.

Dentre as centenas de epigramas dedicados a mulheres no periodo, não há paralelos com os quais possamos lidar para compreender a injunção "ama os meus" no epitáfio de Mélita. Nossa melhor pista a esse respeito provém de uma tragédia de Euripides, mais especificamente Alceste. Porém, antes de enveredar por esse caminho comparativo, é preciso esclarecer por que proponho a correlação entre o epitáfio e a peça de Eurípides, dado que são temporalidades diferentes, lugares diferentes e textos de natureza muito diversa.

A primeira hipótese a descartar é a da intertextualidade, na medida em que, por ela, seja compreendida a necessidade de influên- 
cia direta pela qual teriamos que inferir que o autor e/ou os comanditários do epigrama teriam conhecimento do texto ou da peça de Euripides, e teriam procedido em acordo com uma intenção consciente de imitar as figuras trágicas como as de Alceste e Admeto. É possivel que assim se tenha passado, mas, além de ser uma hipótese que não se pode provar facilmente - teriamos que supor, por exemplo, que os textos das peças circulavam naquele local e época determinados, ou que reapresentações eram encenadas com uma certa frequência, de modo que as peças e suas personagens e enredos faziam parte do imaginário etc. -, o fato de autores e comanditários terem ou não imitado conscientemente algo que viram ou leram não é de todo relevante para o nosso propósito, que deve ser o de compreender o epitáfio de Mélita e reinserir o táphos em um contexto (de interações humanas). Assim sendo, uma segunda hipótese deve autorizar a investigação: ao produzir a tragédia Alceste (438 a.C), Euripides tinha em mente uma trama; mas para enredar essa trama, o autor, sujeito de uma produção inserido em uma comunidade de interpretação, precisaria lidar com expectativas partilhadas em relação a um horizonte de referências de senso comum aos ritos funerários (hábitos, práticas, crenças, espaços etc.). Não se trata primariamente de intertextualidade, mas de uma prática discursiva aplicada sobre uma radical contextualidade.

Esta seria, portanto, a hipótese a desdobrar: não apenas o epitáfio de Mélita mas ainda a tragédia de Eurípides são, do ponto de vista de seus lugares de produção, tributários de uma experiência partilhada, coletiva, da morte em seus ritos, hábitos, em sua pluralidade de idéias e de espaços. Para simplificar: há algo na Alceste, de Euripides, que explora um ponto importante do evento (social) da morte de um consorte, e este algo liga o enredo de Euripides ao epitáfio de Mélita.

Na primeira parte da tragédia Alceste, Eurípides coloca em cena um processo de vigilia e, depois, de lamentação pública pela morte da rainha Alceste, a boa esposa de Admeto. Desde os primeiros cantos do coro, fica claro que, ao decidir tomar o lugar do marido e morrer,
Alceste ganha renome e admiração pública que reverbera no teatro, unindo as palavras do coro ao reconhecimento dos espectadores:

Corifeu: - Alceste, que em minha opinião e na de todos, veio a ser a mais nobre dentre as mulheres [aristê] para seu esposo. (vv. 84-5; trad. da autora)

Como em grande parte dos epitáfios femininos do periodo entre 430-350 a.C., as lamentações do coro pela iminência da morte de Alceste suscitam elogios à sua nobreza, virtude, glória, elogios que definem uma tradição de renome público ligada à poesia. Em nenhum momento da peça é dito de Alceste ser "valorosa" (chresté), mas isto era de se esperar, já que o atributo chresté será difundido apenas a partir de meados do século IV a.C., ligando-se mais à vida doméstica do que ao renome público do indivíduo comemorado. Portanto, não é no elogio em si que encontraremos um caminho para a comparação.

Outrossim, devemos prestar atenção ao lamento de Admeto e ao da própria Alceste, que aparecem no texto da peça de Eurípides contrastando com formas ideais, esperadas, de comportamento tanto do marido como da esposa. No primeiro episódio, a serva descreve a maneira como Alceste se despede da vida com retidão e comedimento. Quando se vê diante do leito do casal, porém, a rainha derrama copiosas lágrimas:

Serva: - Então ela entrou em seu quarto. Aqui finalmente ela chorou e disse, "Oh, leito nupcial onde desfiz o laço e ofereci minha virgindade ao homem por quem hoje morro, adeus! Não te odeio, embora sejas sozinho a causa de minha morte: por não ter desejado abandonar a ti e ao meu marido, agora morro. E tu serás o bem de uma outra mulher, que não terá mais virtudes do que eu, embora talvez mais ventura". Ela caiu sobre o leito e o beijou, molhando-o todo com um rio de lágrimas. (vv. 175-184)

No segundo episódio, Alceste e Admeto entram na cena. Admeto parece fora de si, na dor e no luto:

Admeto: - Ai, palaura de dor / mais mortal para mim que a própria morte! / Em 
nome dos deuses, recusa-te a me abandonar. / Em nome dessas crianças que serão órfãs, / recue, coragem. Tu morta, ah! Que será de mim! / Em ti está minha vida, em ti está minha morte / Pois venero o teu amor. (vv. 273-9)

Percebe-se a imagem de devastação que o poeta quer conferir à sua personagem em luto. Mas ao interagir com esta forma explícita da manifestação do luto e da dor, Alceste não fala nos mesmos termos. Em palavras cantadas de lamento, Alceste chora pela terra que abandona, pelos filhos, pela luz do dia e por sua juventude. $\mathrm{O}$ amor conjugal não aparece em suas falas, mas é possivel depreendê-lo do ato descrito pela serva: abraçar e beijar o leito. Contudo, não se trata, aí, de amor pelo marido. $\mathrm{O}$ apego ao leito tem, de fato, uma conotação quase "legalista": demarcador de um status, esposa e rainha, morrendo Alceste o deixa vazio para ser ocupado por uma outra mulher. Assim, nem em palavras nem em ações Alceste compõe com Admeto uma relação entre philoi, entre amantes. Diante da philia por Admeto, venerada na iminência de sua morte, Alceste replica em lamentação, de forma direta e longamente, manifestando, enfim, um designio final:

Alceste: - Vedes, Admeto, em que estado me encontro. Antes de morrer quero que saibas o que desejo. Eu te respeitei a ponto de dar a minha própria vida para resguardálo à luz do dia. Morro, quando poderia ter sobrevivido a ti e me unido ao homem tessálio de minha escolha, vivendo nesta casa opulenta e soberana. Mas separada de ti recusei viver com meus filhos órfãos, e desprezei a felicidade que tinha de ser jovem e estar viva. (...) Bem, então, lembra-te de mostrar tua gratidão por isso. Não pedirei um dom equivalente em retribuição pois nada é mais precioso que a vida, mas solicito o que é justo, como verás. Pois tu amas nossos filhos tanto quanto eu, se tens bom juizo. Cuida então para que em minha casa eles permaneçam os mestres e não tomes outra mulher que seria para eles madrasta, menos nobre que eu e que, com inveja, se voltaria contra nossos filhos. (vv. 280 e ss.)
A demarcação pública, social, do lugar dos filhos é a resposta da esposa exemplar à philia do marido. De fato, a ansiedade com relação ao destino dos filhos diante da possibilidade de um novo casamento não é um tema específico de Alceste, mas se encontra ainda em diversas outras peças de Eurípides (Medéia, Andrômaca, Electra, Orestes) e ainda em Ésquilo (Coeforas). Acredito que esta mesma ansiedade se apresenta no epitáfio de Mélita quando, em resposta à interpelação de seu consorte, pede: “tous émous philei”. Mélita requisita publicamente, em voz alta a cada leitura do epitáfio, que Onésimo ame os filhos dela.

A Andrômaca, de Euripides, foi privada de seus filhos e é cativa na casa de Neoptólemo, cuja esposa legitima é a filha de Helena, Hermione. Por ser uma boa mulher, Andrômaca sofre com os ciúmes de Hermíone, a quem os deuses não concedem ter filhos sendo, por isso, seus filhos os únicos filhos de Neoptólemo. Medéia, por sua vez, é estrangeira. Ao ver-se diante da traição de um juramento sobre o leito, usa de um estratagema para se vingar do marido: finge pedir a ele que cuide de seus filhos, apesar das novas núpcias. O pedido é prontamente aceito, mesmo com o risco de que um mal advenha dessa concordância; ao que parece, a nova esposa teria aceitado encarregarse das crianças. Alceste, por fim, é boa e legitima esposa, mas esse estatuto não garante o bem-estar de seus filhos em caso de separação ou morte. É preciso utilizar um momento de lamentação, de luto, para requisitar a Admeto que, por amor aos filhos, não venha a ocupar o lugar da mãe com outra mulher. A levar em conta o modo como o teatro trágico a tematiza, vemos que a ansiedade envolvendo o futuro dos filhos perpassa diversas condições de status das mulheres.

\section{Uma trama em um contexto}

Apesar da relativa frequência com que aparece no teatro de Euripides, a preocupação com o futuro dos filhos não está presente da mesma maneira explicita em outros epitáfios de periodos anteriores ou contem- 
porâneos ao de Mélita. É possivel argumentar que o próprio ato do elogio das esposas pelos epigramas funerários, concedendo a elas renome público, funcionaria como uma forma de garantia para os filhos. E que o ato de explicitar a requisição realizaria algo a mais, desnecessário a não ser em uma situação-limite, como o exílio de Medéia, a escolha "viril" de Alceste ou a desgraça de Andrômaca. Vale lembrar que esses casos liminares da Tragédia ressaltam, todos, a singularidade de uma figura feminina altamente independente - ou sozinha?

Estou sugerindo, portanto, que a Mélita a quem o amante Onésimo dedica um táphos encontrava-se em uma situação-limite. A iconografia de sua estela confunde-se com a iconografia de diversas outras estelas funerárias que, em larga medida, apontam para um universo de relações domésticas regulares e valorizadas. O epigrama, contudo, confere uma tonalidade afetiva ao relacionamento de um casal especifico. Não estamos mais, aqui, no domínio dos valores abstraidos, mas antes no âmbito da vida comum, do cotidiano. Nesse domínio em que pesam os familiares ou amigos, os conhecidos ou os forasteiros, o epigrama a Mélita lida com a afetividade, com a comoção de quem o escuta, para funcionar não como memorial de familia a uma filha, mãe, esposa, ama etc., mas como um ato quase juridico de palavra, como discurso não institucionalizado de direito. Ao final, podemos suspeitar que é o reconhecimento cotidiano, coletivo, da condição de Mélita (mulher amada em retorno, valorosa) que deve exercer pressão sobre Onésimo para amar (preservar) seus filhos. E esse reconhecimento cotidiano não se constrói simplesmente sobre a leitura (racionalizada) do epigrama dedicado a Mélita, mas pela apreensão afetiva, interessada e majoritariamente visual, do conjunto do táphos.

O táphos de Mélita é singular. Mas sua singularidade pode nos indicar uma regra sobre como reivindicar um direito, uma posição, quando não se domina os meios institucionais de pressão. Futuramente, quando se resolver analisar o conjunto das centenas de dedicações funerárias a mulheres na Ática, essa possibilidade de pressão sobre uma comunidade institucionalmente desfavorável deve fundamentar o trabalho, de preferência a problemáticas já muito estudadas, como a da busca de um status definido na esfera predominante da cidadania (Nielsen 1989: 411-420; Leader 1997: 683-699; Osborne 1997:3-33.; Burton 2003: 20-35).

\section{Pós-Escrito}

Depois de finalizar esse texto, coloquei-o em discussão junto ao grupo de estudos que coordeno no âmbito do Laboratório de História Antiga da UFRJ. O tema do grupo é a leitura histórica e o ofício do Historiador e, ao longo do primeiro semestre de 2010, estamos justamente promovendo debates em torno da análise de diversos tipos de materiais, desde a literatura até a iconografia e a cultura material. Tenho que mencionar aqui algumas sugestões que me foram dadas pela doutoranda Irina Aragão dos Santos (PPGHC-UFRJ). Formada em Belas Artes e História, professora do curso de Design da PUC-RJ, seu olhar foi levado diretamente para a composição da estela funerária. Ela observou que, diante da estela inteira, percebe-se a diferença entre o antêmio esculpido na parte superior e o relevo iconográfico no centro. O primeiro é cuidadosamente moldado, demonstrando uma técnica superior àquela que produziu ou àquelas que produziram - o entalhe central e o epigrama. Assim, enquanto eu tendia a ver a estela como um produto sincrônico, um artefato modelado de uma vez só e inacabado, Irina sugeriu que havia diacronia no trabalho aplicado ao mármore: num primeiro momento, esculpida na pedra lisa, deve ter sido a parte superior; num segundo momento, provavelmente após a venda, gravaram-se os elementos iconográficos e textuais na parte lisa. Assim, o entalhe iconográfico e a dedicação funerária podem ter sido acrescentados a uma estela funerária pré-existente, por mãos menos hábeis do que as que se ocuparam com a escultura do antêmio; mãos que descuidaram, por exem- 
plo, da proporção entre as dimensões da cadeira (klismos) e dos corpos do homem e da mulher; descuidaram, ainda, das proporções do braço direito, grande demais para o tronco e a cabeça da figura feminina.
Suspenderei as considerações e as hipóteses para uma outra oportunidade, e deixo-me ficar aqui no reino do talvez; privilégio dos pósescritos. Obrigada a Irina e a todos os estudantes que participam do grupo.

ANDRADE, M.M. Praising women in funerary contexts of classical Athens: a case study of Melite's táphos. Revista do Museu de Arqueologia e Etnologia, São Paulo, 20: 235-249, 2010.

\begin{abstract}
This paper analyses a funerary stele from the Piraeus Archaeological Museum (inv. 20), inside a wider scope of funerary steles with carved dedications to women in Archaic and Classical Attica. It raises some important questions about theory and methodology in the field of gender studies in general, and on women's history in particular, dealing with hypothesis on normative ideals and their (flexible) uses by polis's society, concerning marriage, love and women's public display.
\end{abstract}

Keywords: Iconography - Epigraphy - Funerary contexts - Philia Women's public display - Classical Athens - Gender relations.

\title{
Referências bibliográficas
}

ANDRADE, M.M.

2009 O espaço funerário: dedicações privadas e exposição pública das mulheres em Atenas (sécs. VII-IV a.C). In: Ciclo de Debates em História Antiga. Conferência não publicada. Rio de Janeiro: LHIA/ UFRJ.

BENSON, C.A.

1996 Recurring Figure-Types on Classical Attic Grave Stelai. Ann Arbor: University of Michigan. Monografia.

BENVENISTE, É.

1969 Le Vocabulaire des Instituitions IndoÉuropéennes. Paris: Les Editions de Minuit, 2 vols.

BURTON, D.

2003 Public Memorials, private virtues: women on classical athenian grave monuments. Mortality, 8 (1): 20-35.
CALAME, C.

1996 L'Éros dans la Grèce Antique. Paris: Belin.

CLAIRMONT, C.

1970 Gravestone and Epigram. Mainz: Von Zarbern (GaE)

1993 Classical Attic Tombstones. Kilchberg: Akanthus; 9 vols (CAT)

CLOSTERMAN, W.E.

1999 The self-presentation of the family: the function of classical attic peribolos tombs. Ann Arbor: PhD Phil. Thesis, John Hopkins University.

DAVIES, G.

1985 The Significance of the Handshake Motif in Classical Funerary Art. American Journal of Archaeology, 89: 627-640.

GARLAND, R.

1985 The Greek Way of Death. Ithaca: Cornell University Press. 
1989 The Well Ordered Corpse. Bulletin of the Institute of Classical Studies, 36: 1-15.

HANSEN, P.A.

1983 Carmina Epigraphica Graeca Saeculorum VIII-V a. Chr. n. Berlin: Walter de Gruyter (CEG).

1989 Carmina Epigraphica Graeca Saeculi IV a. Chr. n. Berlin: Walter de Gruyter (CEG 2).

HUMPHREYS, S.

1983 Family Tombs and Tomb Cult in Classical Athens: tradition or traditionalism? The Family, Women and Death. London: Routledge \& Kegan Paul: 79-130.

JOHANSEN. K.F.

1951 The Attic Grave-Reliefs of the Classical Period. An Essay in Interpretation. Copenhagen: Ejnar Munksgaard.

KONSTAN, D.

1997 Friendship in the Classical World. Cambridge: Cambridge University Press.

LEADER, R.E.

1997 In Death not Divided: gender, family and state on classical athenian grave stelae. American Journal of Archaeology, 101 (4): 683-699.

LIDELL, H.G.; SCOTT, R.

1996 Greek-English Lexicon. With a Revised Supplement. Oxford: Clarendon Press (LSJ).

LISSARRAGUE, F.

1991 Femmes au Figuré. In: Duby, G.; Perrot, M.; Schmitt-Pantel, P. (Eds.) Histoire des Femmes en Occident (Vol. 1 : L'Antiquité). Paris: Plon : 159-251.

1995 Women, Boxes, Containers : Some Signs and Metaphors. In: Reeder, E. (Ed.) Pandora. Women in Classical Greece. Princeton, UPress: 91-101.

MORRIS, I.

1992 Death Ritual and Social Structure in Classical Antiquity. Cambridge: Cambridge University Press.
1993 Law, Culture and Funerary Art in Athens. Hephaistos, 11-12: 35-50.

NIELSEN, T.H.; BJERTRUP, L., HANSEN, M.H.; RUBENSTEIN, L.; VESTERGAARD ,T.

1989 Athenian Grave Monuments and Social Class. Greek, Roman and Bizantine Studies, 30 (3): 411-420.

OSBORNE, R.

1997 Law, the Democratic Citizen and the Representation of Women in Classical Athens. Past and Present, 155: 3-33.

PEEK, W.

1988 Griechische Vers-Inschriften. I. GrabEpigramme. Chicago: Ares Publishers [1955] (GV).

PEMBERTON, E.G.

1989 Dexiosis on Attic Gravestones. Mediterranean Archaeology, 2: 45-50.

REDFIELD, J.

1994 O Homem e a Vida Doméstica. In: Vernant, J.-P. (Ed.) O Homem Grego. Lisboa: Editorial Presença: 147-171.

REHM, R.

1994 Marriage to death: the conflation of wedding and funeral in Greek tragedy. Princeton: Princeton University Press.

SCHEIN, S.

1988 Philia in Euripides Alcestis. Metis, 3 (1-2): 179-206.

SEGAL, C.

1992 Euripides' Alcestis: Female Death and Male tears. Classical Antiquity, 11 (1): 142-171.

SOURVINOU-INWOOD, C.

1995 Reading Greek Death. Oxford: Clarendon Press.

YOUNGER, J. G.

2002 Women in Relief: "Double-Consciousness" in Classical Attic Tombstones. In: Rabinowitz, N.S.; Auanger, L. (Ed) Among Women. From the Homosocial to the Homoerotic in the Ancient World. Austin: University of Texas Press: 167-210. 